\title{
Interaction between avian influenza subtype H9N2 and Newcastle disease virus vaccine strain (LaSota) in chickens
}

\author{
Hany F. Ellakany ${ }^{1}$, Ahmed R. Gado ${ }^{1}$, Ahmed R. Elbestawy ${ }^{1 *}$, Hatem S. Abd El-Hamid ${ }^{1}$, Hafez M. Hafez², \\ Mohamed E. Abd El-Hack ${ }^{3^{*}}$ (D) Ayman A. Swelum ${ }^{4,5^{*}}$, Abdullah Al-Owaimer ${ }^{4}$ and Islam M. Saadeldin ${ }^{4,6}$
}

\begin{abstract}
Background: H9N2 avian influenza virus is endemic in Egyptian poultry flocks. The role of the live viral vaccines such as LaSota in exaggeration of the clinical picture of H9N2 infection under field conditions is significantly important leading to severe economic losses due to higher mortality and lower growth performance. This experiment was designed to identify the possible interaction between experimental infection with H9N2 virus and NDV live vaccine (LaSota strain) in broiler chickens. Six groups each of 20 broiler chicks were used. Three groups (G1-3) were infected with H9N2 and vaccinated with LaSota, 3 days before, at the same day or 3 days post vaccination (dpv), while the remaining groups (G4-6) were non-vaccinated infected, vaccinated non-infected and non-vaccinated non-infected.

Results: The highest mortality rate (37.5\%) was noticed in chickens of G1 (H9N2 infected 3 days prior LaSota vaccination). Also, this bird group had the most severe clinical signs, histopathological lesions and the longest viral shedding for 9 days post infection (dpi). In the 2 nd and 3rd groups, the mortality rate was the similar (31.2\%) with less pronounced clinical signs, histopathological lesions and H9N2 shedding was for only 6 dpi with the least shedding quantity in chickens of G3. The control non-vaccinated infected chickens (G4) had 18.7\% mortality with the least degree of clinical signs, lesions and the highest viral shedding quantity but only for 6 dpi. At 35 days of age, there was a statistical significant decrease $(P<0.05)$ in chicken's body weight of all H9N2 infected groups from G1 to G4 compared to non-infected control groups, G5 and G6 respectively.
\end{abstract}

Conclusion: It was clear that laSota vaccination significantly affect H9N2 infection in broiler chickens regarding clinical signs, mortality rate, lesions, performance and viral shedding.

Keywords: Interaction, Avian influenza, H9N2, LaSota, NDV

\section{Background}

Low pathogenic avian influenza (LPAI) subtype H9N2 virus is widespread worldwide, being endemic in poultry populations in Asia and the Middle East. The first isolation of H9N2 virus in Egypt was obtained from the apparently healthy commercial bobwhite quail flock (A/quail/Egypt/

\footnotetext{
* Correspondence: ahmed.elbestawy@vetmed.dmu.edu.eg;

dr.mohamed.e.abdalhaq@gmail.com; m.ezzat@zu.edu.eg; aswelum@ksu.edu.sa

${ }^{1}$ Department of Poultry and Fish Diseases, Faculty of Veterinary Medicine, Damanhour University, Elgomhoria st, 63, Damanhour, Elbehira 22511, Egypt ${ }^{3}$ Department of Poultry, Faculty of Agriculture, Zagazig University, Zagazig 44511, Egypt

${ }^{4}$ Department of Animal Production, College of Food and Agriculture Sciences, King Saud University, P.O. Box 2460, Riyadh 11451, Saudi Arabia Full list of author information is available at the end of the article
}

113413v/2011/H9N2) in May 2011 [17]. Later on, the virus was isolated from commercial broiler, broiler breeder and layer flocks [27, 32]. H9N2 AIV infection in broilers cause reduction of growth rate and adverse the feed conversion ratio. In addition, high mortality rate appeared in case of co-infection with other pathogens such as infectious bronchitis virus (IBV), Newcastle disease virus (NDV), Staphylococcus aureus, Ornithobacterium rhinotracheale and E. coli or immune suppression, which exacerbates H9N2 influenza A virus infection in chickens $[18,23]$. Lentogenic NDV strains are commonly used as live vaccines in the commercial poultry industry to protect from virulent forms of NDV. Experimental infections of specific pathogen-free (SPF) chickens with NDV vaccine strains cause little to no clinical disease. However, the application of the vaccine

(c) The Author(s). 2018 Open Access This article is distributed under the terms of the Creative Commons Attribution 4.0 International License (http://creativecommons.org/licenses/by/4.0/), which permits unrestricted use, distribution, and 
under field conditions can decrease productivity by inducing mild respiratory symptoms, which could be exacerbated concomitantly with other respiratory pathogens or in combination with environmental stressors [33]. Viral interference is a phenomenon explained previously [13], in which the infected cells by a virus do not permit multiplication of a second virus. Both viruses (LPAI and NDV) replicate in the epithelial cells of the respiratory and intestinal tracts (where trypsin-like enzymes is present) through competing for target cells or replicating in adjacent cells exacerbating clinical signs of disease in infected birds or produce viral interference, masking infections in one of them $[9,38]$.

In this experiment, we studied the interaction between LPAI subtype H9N2 infection and NDV vaccine (LaSota strain) in broiler chickens regarding clinical signs, body weights, post-mortem lesions, mortality, viral shedding, histopathological lesions and serological response for both viruses.

\section{Results}

\section{Clinical signs (Table 1)}

The observed signs in all infected groups with H9N2 virus (G1-4) were depression, decreased feed consumption and respiratory signs. The most severe clinical signs in terms of morbidity were observed in chickens of G1, while the least were in chickens of G4 as the respiratory signs started by sneezing and coughing then exaggerated as rales, nasal discharge, and head swelling till the end of observation period (21 days). Also, white greenish diarrhea was observed from 3rd dpi and subsiding at 11th -12th dpi. In addition, only in G1 exhibited thick oral mucous, which started at 7th dpi and continued until end of observation period.

\section{Daily mortality (Table 2) and post-mortem (PM) lesions}

Chickens of G1 suffered from early highest mortality 6/ 16 birds (37.5\%) from 7th to 17th dpi compared to $31.2 \%$ (5/16 birds) in both G2 and G3 which began from 8 th to 15 th and 2nd to 9th dpi, respectively in both groups. While, in G4, the mortality rate was $18.7 \%$ (3/16 birds) with delayed start at day 12th dpi and continued only for 3 days.

Table 1 Degree of severity of clinical signs

\begin{tabular}{|c|c|c|c|c|c|c|}
\hline Chicken groups & G1 & G2 & G3 & G4 & G5 & G6 \\
\hline \multicolumn{7}{|l|}{ Clinical signs } \\
\hline Sneezing & +++ & ++ & ++ & + & - & - \\
\hline Coughing & +++ & ++ & ++ & + & - & - \\
\hline Rales & +++ & ++ & ++ & + & - & + \\
\hline Head swelling & +++ & ++ & + & - & - & - \\
\hline Diarrhea & +++ & ++ & ++ & + & - & - \\
\hline Depression & +++ & ++ & ++ & + & - & - \\
\hline Thick oral saliva & +++ & - & - & - & - & - \\
\hline
\end{tabular}

-: No signs +: Mild degree ++: Moderate degree +++: Severe degree
Table 2 Mortality rates in all experimental chicken groups from 15 to 35 DO after infection with LPAI subtype H9N2 alone or in combination with LaSota vaccine

\begin{tabular}{|c|c|c|c|c|c|c|c|}
\hline \multirow{2}{*}{$\begin{array}{l}\text { Age } \\
\text { (days) }\end{array}$} & \multirow[t]{2}{*}{ dpi } & \multicolumn{6}{|c|}{ Daily mortality/each chicken group } \\
\hline & & 1 & 2 & 3 & 4 & 5 & 6 \\
\hline 15 & 1 & - & - & - & - & - & - \\
\hline 16 & 2 & - & - & - & - & - & - \\
\hline 17 & 3 & - & - & - & - & & - \\
\hline 18 & 4 & - & - & - & - & - & - \\
\hline 19 & 5 & - & - & - & - & - & - \\
\hline 20 & 6 & - & - & - & - & - & - \\
\hline 21 & 7 & 2 & - & - & - & - & - \\
\hline 22 & 8 & 1 & - & - & - & - & - \\
\hline 23 & 9 & 2 & - & 1 & - & - & - \\
\hline 24 & 10 & - & - & - & - & - & - \\
\hline 25 & 11 & - & - & - & - & - & - \\
\hline 26 & 12 & - & 1 & - & - & - & - \\
\hline 27 & 13 & - & - & - & - & - & - \\
\hline 28 & 14 & - & - & - & - & - & - \\
\hline 29 & 15 & - & - & 1 & - & - & - \\
\hline 30 & 16 & - & - & 1 & 1 & - & - \\
\hline 31 & 17 & 1 & 1 & 1 & 1 & - & - \\
\hline 32 & 18 & - & 2 & 2 & 1 & - & - \\
\hline 33 & 19 & - & 1 & - & - & - & - \\
\hline 34 & 20 & - & - & - & - & - & - \\
\hline 35 & 21 & - & - & - & - & - & - \\
\hline \multicolumn{2}{|c|}{ Mortality No. } & $6 / 16$ & $5 / 16$ & $5 / 16$ & $3 / 16$ & $0 / 16$ & $0 / 16$ \\
\hline \multicolumn{2}{|c|}{ Percent \% } & 37.5 & 31.2 & 31.2 & 18.7 & 0 & 0 \\
\hline
\end{tabular}

The most prominent PM lesions appeared were tracheitis, pneumonia, air sacculitis, splenomegaly, pancreatitis, enteritis, and nephritis. Chickens of G1 were more affected than other groups in terms of frequency and severity of lesions. No thymus, bursal lesions or caseous plug at tracheal bifurcation were observed.

No clinical signs, mortalities or PM lesions were recorded in G5 and G6.

\section{Body weights of the experimental groups}

All chicken groups had no significant difference at 14th day of age. On the other hand, a significantly decrease of body weight were observed in chickens of G1, G3 and G4 $(P<$ 0.05 ) in compare to the birds of G2, G5 and G6 at 21th day of age. At 28th day, all vaccinated and infected chickens $(\mathrm{G} 1, \mathrm{G} 2$ and G3) were significantly decreased $(P<0.05)$ in body weights than G4, G5 and G6. Finally, at 35th day of age the body weights were significantly decreased $(P<0.05)$ in all H9N2 infected groups from G1 to G4 as 1540, 1509, 1474 and $1605 \mathrm{~g}$, respectively than non-infected control G5 and G6 as 1769 and 1782 g, respectively (Fig. 1). 


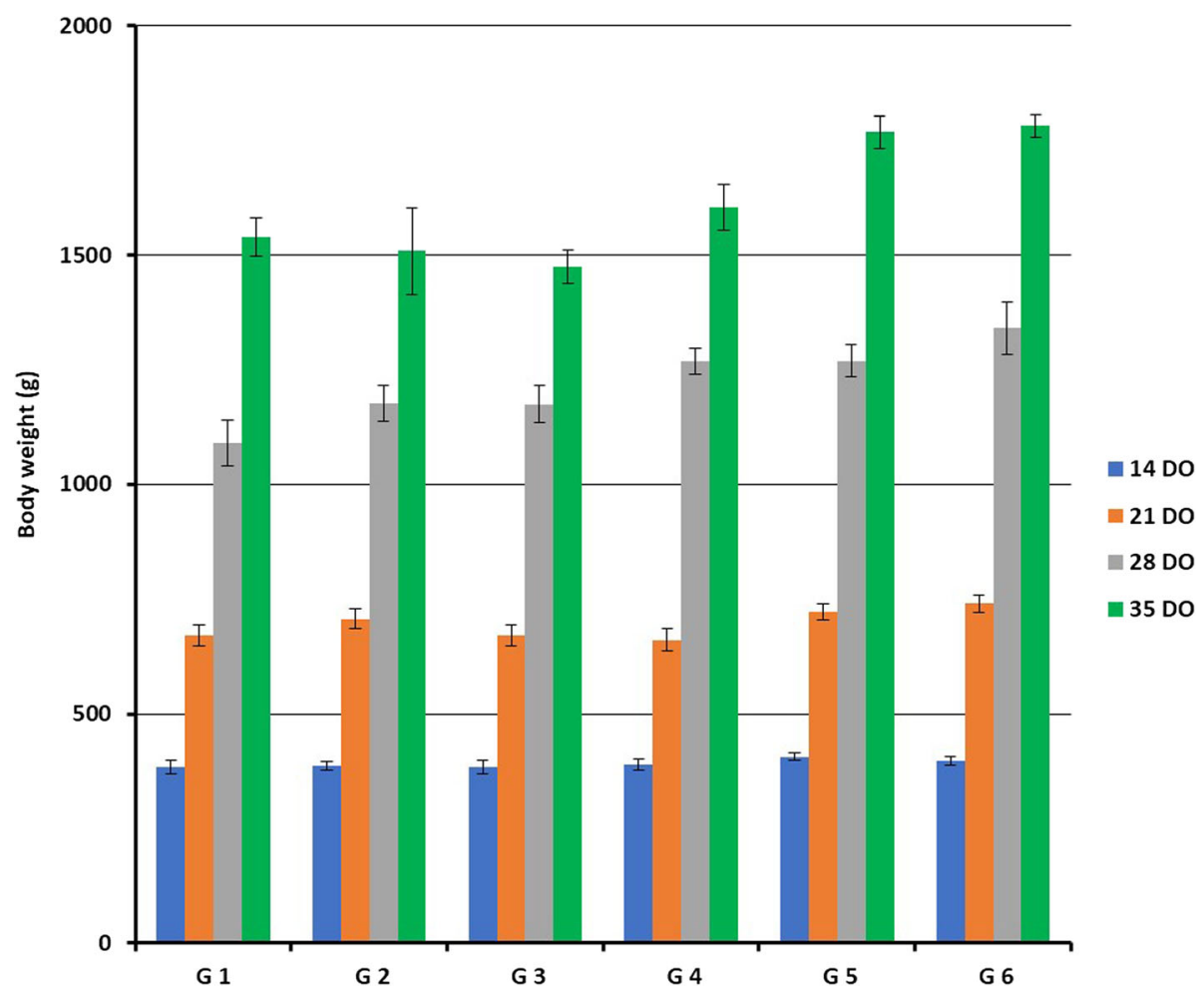

Fig. 1 Mean \pm SE body weight (gram) of all experimental chicken groups at 14, 21, 28 and 35 DO

\section{Histopathology}

Trachea of bird in G1 showed severe degeneration of mucous glands with partial loss of the lining mucosa (Fig. 2a), while other H9N2 infected groups G2, G3 and G4 showed mild to moderate epithelial degeneration and hyperplasia of the mucosal lining (Fig. 2b and c).

Thymus lesions appeared as marked loss of cortical basophilic thymocytes which revealed marked lymphoid depletion was also noticed in the early infected G1 chickens (Fig. 3a). While birds of G4 showed degeneration and marked decrease of cortical thymocytes compared to control chicken G6 (Fig. 3b and c).

Bursa of Fabricius of birds of G1 (Fig. 4a) and G2 showed lesser degree of lymphoid depletion than birds of G3 and G4 (Fig. 4b) which appeared as marked lymphoid depletion with large mucin filled cysts within some follicles and thickening of the interfollicular connective tissue compared to control chicken G6 (Fig. 4c).

Spleen of chicken G1 and G4 (Fig. 5a and b) showed mild to moderate degree of lymphoid depletion, while the examined spleen of all other chicken groups was normal histology (Fig. 5c).

Renal inflammation of chickens G1 (Fig. 6a) and G4 showed lesions of glomerulonephritis which was obvious in most of examined birds. Interestingly, most of the lesions were glomerular rather than tubular and with a diffuse pattern with some tubular interstitial nephritis (Fig. 6b). Other chicken groups were histologically normal (Fig. 6c).

\section{Mean $\mathrm{HI}$ titers of experimental chicken groups}

The mean HI titer of the 10 sacrificed birds at day 1 for H9N2 and NDV were 6.1 and $6.7 \log 2$, respectively.

For H9N2: At 7th dpi, the HI titers of G3 were significantly $(P<0.05)$ lower than $\mathrm{G} 2, \mathrm{G} 4$ or $\mathrm{G} 1$ for (with no significant difference between samples of chicken G1 and G4). While, the only significant lower titers $(P<$ 0.05 ) at 14th dpi were in G1 (4.7) rather than G2, G3 and G4 (6.9, 6.2 and 6.7, respectively).

Regarding NDV: At 7th and 14th dpi, the highest significant $(P<0.05) \mathrm{HI}$ titers were G2, G3 and G5 as 4.2, 4 and 3.9 and $3.7,3.9$ and 4.2 , respectively compared to the lowest significant $(P<0.05)$ titers in $G 4$ at the same dpi as 2.8 and 0.9 , respectively (Table 3 ).

\section{Quantification of H9N2 virus shedding by real-time RT- PCR}

Tracheal swabs collected before challenge then at 3, 6 and 9 dpi revealed that the highest viral titers were in chicken G4 followed by G1, while the least titers were in $\mathrm{G} 3$ at 3 dpi. Also, the shedding of the H9N2 virus was persisted for 9 dpi in G1 only (Fig. 7). 

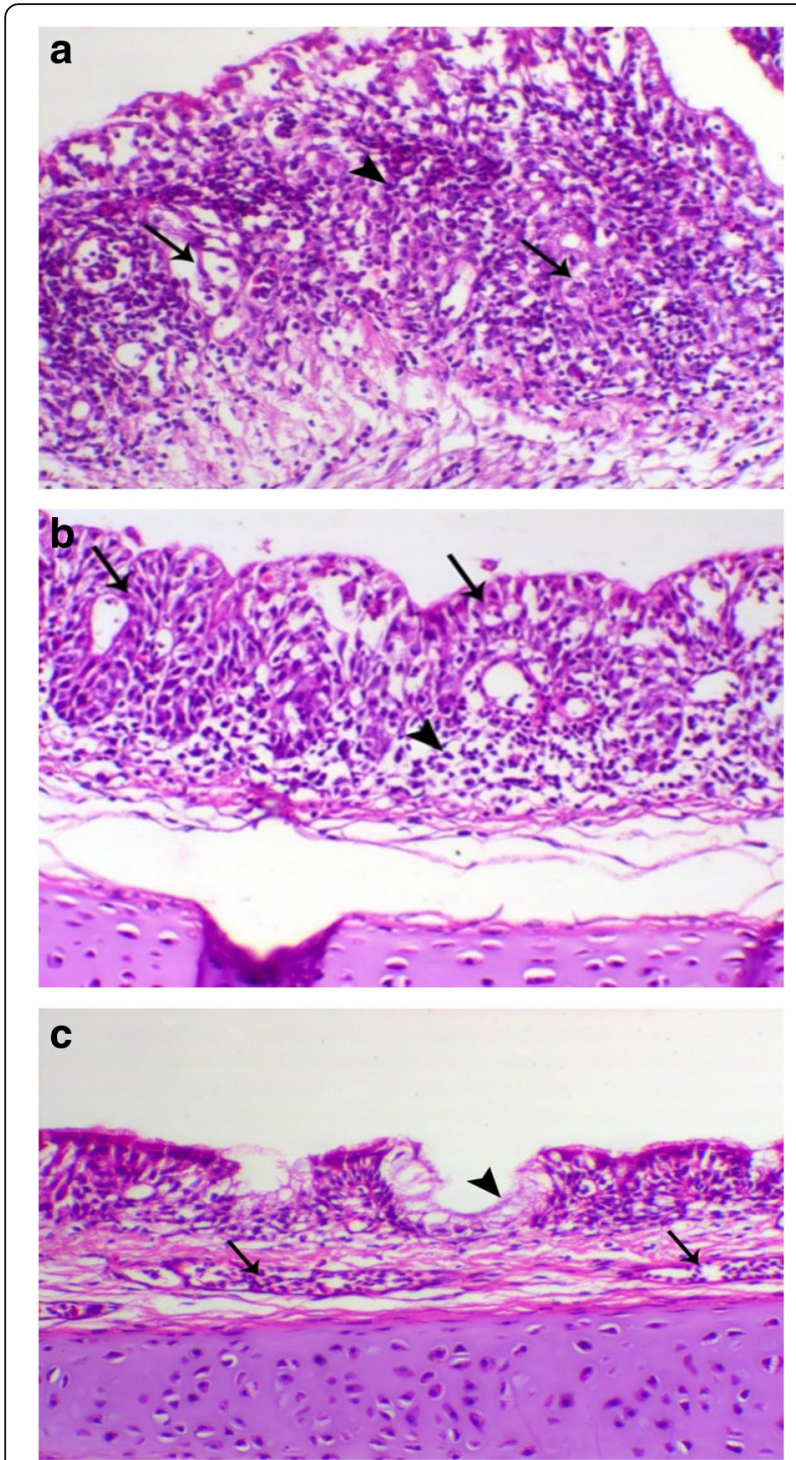

Fig. 2 a Trachea of birds in G1 showed severe degeneration of the tracheal mucous glands (arrow) with marked leukocytic infiltration. H\&E, X 200; b Trachea of in G2 showed epithelial and glandular degeneration (arrow) and lower sub-epithelial leukocytic infiltration (arrowhead), H\&E, X 200; c trachea of non-infected non-vaccinated chicken G6 showed normal epithelial lining (arrowhead) contained blood vessels (arrow), H\&E, X 200

\section{Discussion}

Co-infections between LPAI subtype H9N2 and NDV usually occur, but cannot be easily diagnosed due to confusing similar clinical signs [38]. However, H9N2 infection is mostly associated with elevated mortality and severe economic losses due to many factors such as bad management, concurrent bacterial or viral diseases, live IBV or NDV vaccines, immune suppressive agents, age at the infection and the breed of chickens, which are mostly influenced the course of H9N2 infections $[1,9,20,29]$.
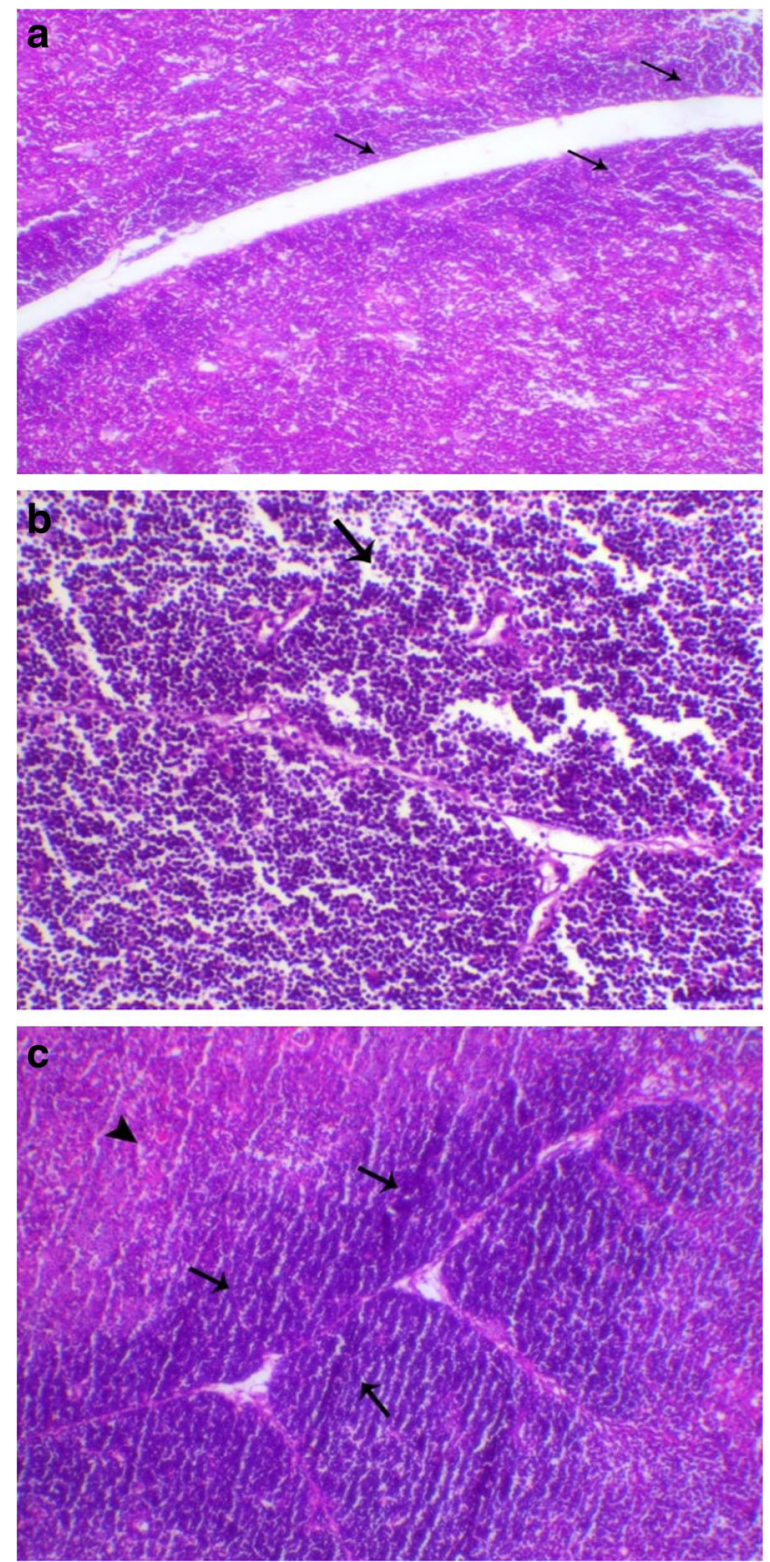

Fig. 3 a Thymus of bird in G1 showed severe loss of cortical basophilic thymocytes H\&E, X 100; $\mathbf{b}$ Thymus of birds in G4 showed a marked decrease of cortical thymocytes (arrow), H\&E, X 200; c Thymus of control chicken $G 6$ revealed normal cortex and medulla with marked distinction between each. H\&E, X 200

In the present work, we studied the interaction between both LPAI subtype H9N2 infection and vaccination with lentogenic NDV (LaSota strain) under experimental condition.

No clinical signs were observed in G5 and G6 (non-infected groups), while infected and non-vaccinated G4 exhibited mild respiratory signs (without head swelling) and diarrhea. All groups infected and vaccinated with LaSota showed more severe clinical signs started from 3 dpi and continued until the end of the observation 

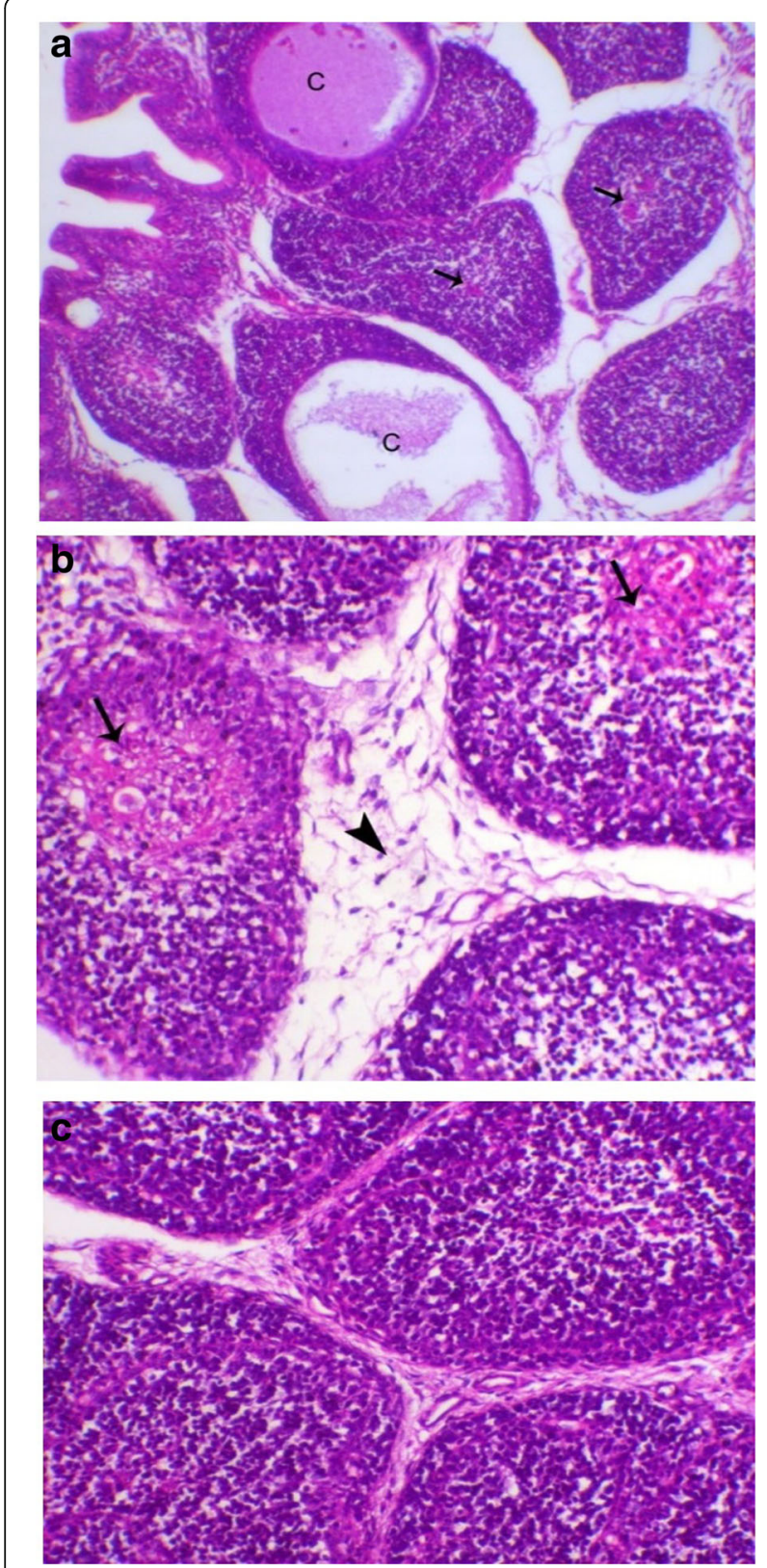

Fig. 4 a Bursa of birds in G1 revealed lymphoid depletion (arrow) with large mucin filled cysts within some of follicle (c). H\&E, X 100; b bursa of birds in G4 showed lymphoid depletion with appearance of reticular fibers in the medulla of lymphoid follicle (arrow), and with marked increase in thickness of interfollicular connective tissue

(arrowhead). H\&E, X 200; c bursa of Fabricius of birds in G6 showed normal bursal lymphoid follicles. H\&E, X200

period except diarrhea that stopped after 7 days from its appearance. Interference between $\mathrm{H} 9 \mathrm{~N} 2$ and vNDV was studied by Bonfante, et al. [8] who reported that the H9N2 challenge made birds more susceptible to the vNDV, lowering the minimum dose required to cause an infection, exacerbating the clinical outcome, while delaying the onset of the disease and time of death.
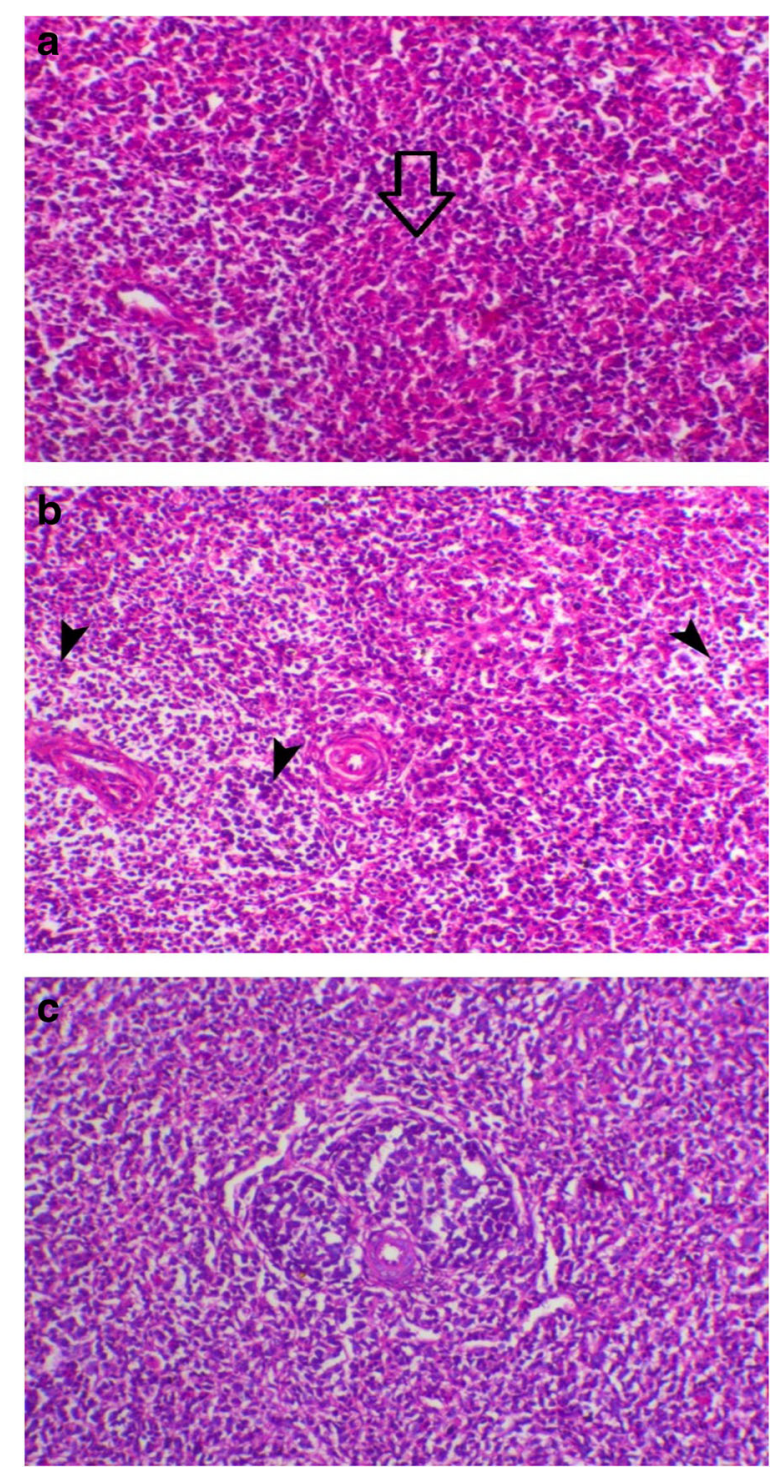

Fig. 5 a Spleen of G1 birds showed absence of lymphoid follicle (arrow). H\&E, X 200; b Spleen of birds in G4 (non-vaccinated and H9N2-infected) showed decrease of lymphoid follicle (arrowhead). H\&E, X 200; c Spleen of birds in G6 showed normal lymphoid follicle. $H \& E, X 200$

The highest severity of signs was recorded specially in chickens of G1 at 3-6 dpi concurrently with high H9N2 viral shedding in this group compared to G4 as detected by rRT-PCR, the results are in agreement with the findings detected by Kwon, et al. [24], which observed that following infection with an LPAI H9N2 virus, the clinical sign was peaked on $6 \mathrm{dpi}$. In the present study, diarrhea and dullness of the birds were observed after $2 \mathrm{dpi}$, reached its maximum at $5 \mathrm{dpi}$ and started to decline at 8 dpi, which is like the findings of Aslam, et al. [4].

Regarding the mortality, the chickens of G3 were suffered from early mortality at 2nd dpi and persisted till 

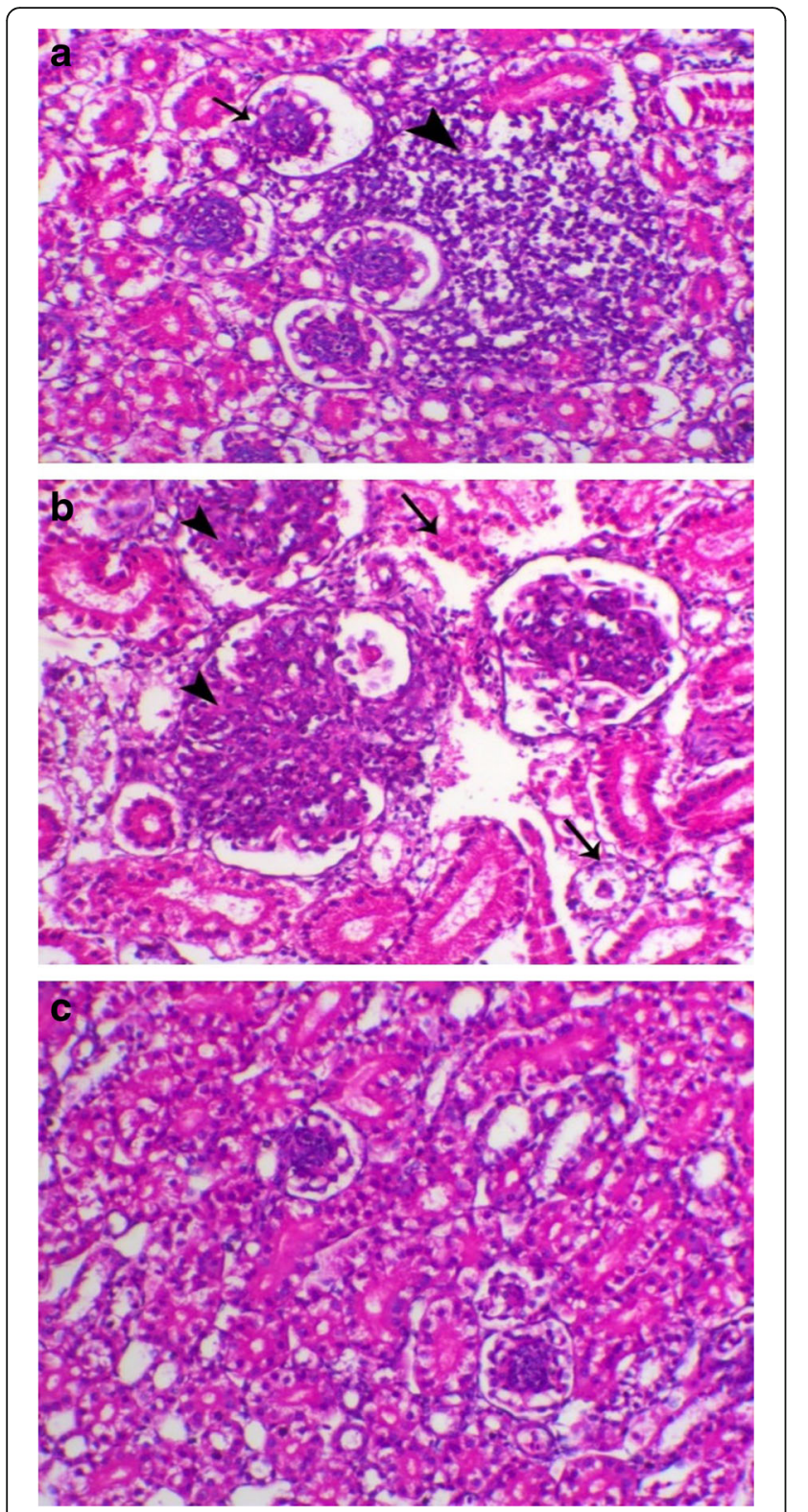

Fig. 6 a Kidney of G1 birds showed periglomerular and peritubular inflammatory cells infiltrations mainly lymphocytic (arrowhead). H\&E, X 200; b Kidney of G4 birds showed marked glomerulonephritis features which revealed loss of capillaries and hypercellularity (arrowhead), with marked degeneration of renal tubules (arrow). H\&E, X 200; c Kidneys of normal birds showed normal renal tubular and glomerular structures. H\&E, X 200

11 dpi while the highest mortality (37.5\%) was observed in G1. The least mortality (18.7\%) was in chicken G4 began from 12th dpi and continued only for 3 days. Some studies reported no mortality after experimental infection of SPF-chickens with H9N2 [6, 8, 26].

This unusual high mortality rate in the present study may be due to the use of commercial broiler and not SPF chicks, which might be naturally carried some
Table 3 Mean \pm SE of HI titers for H9N2 and NDV (Geometric Mean) in different experimental chicken groups at 7th and 14th dpi

\begin{tabular}{llllll}
\hline Group & H9N2 & & & NDV \\
\cline { 2 - 3 } & 7 th dpi & 14th dpi & & 7 th dpi & 14th dpi \\
\hline 1 & $7.1 \pm 0.2 \mathrm{~b}$ & $4.7 \pm 0.2 \mathrm{~b}$ & & $3.8 \pm 0.3 \mathrm{ab}$ & $2.9 \pm 0.3 \mathrm{~b}$ \\
2 & $8.2 \pm 0.3 \mathrm{a}$ & $6.9 \pm 0.3 \mathrm{a}$ & & $4.2 \pm 0.4 \mathrm{a}$ & $3.7 \pm 0.3 \mathrm{a}$ \\
3 & $5.5 \pm 0.4 \mathrm{c}$ & $6.2 \pm 0.5 \mathrm{a}$ & & $4.0 \pm 0.3 \mathrm{a}$ & $3.5 \pm 0.3 \mathrm{a}$ \\
4 & $7.3 \pm 0.3 \mathrm{~b}$ & $6.7 \pm 0.6 \mathrm{a}$ & & $2.8 \pm 0.2 \mathrm{bc}$ & $0.9 \pm 0.2 \mathrm{c}$ \\
5 & $2.0 \pm 0.2 \mathrm{~d}$ & $0.9 \pm 0.3 \mathrm{c}$ & & $3.9 \pm 0.3 \mathrm{ab}$ & $4.2 \pm 0.2 \mathrm{a}$ \\
6 & $2.2 \pm 0.2 \mathrm{~d}$ & $0.8 \pm 0.2 \mathrm{c}$ & & $2.6 \pm 0.4 \mathrm{c}$ & $0.7 \pm 0.2 \mathrm{c}$ \\
\hline
\end{tabular}

$n=10$ serum samples from each group

Mean values with different letters in the same column differ significantly at $P<0.05$

bacterial infection such as Mycoplasma and/or E coli, which are known to exaggerate the mortality of H9N2 infection. Li, et al. [25] found out that infection of SPF chicken with H9N2 virus did not induce any clinical signs or deaths after experimental infection, implying that co-infections with other pathogens might be the cause for these H9N2 viruses to be lethal in the field.

Also, the increase in morbidity and mortality frequency after H9N2 AIV infection could be as a result of viral dissemination and spreading from the nasal cavity, which is the primary site of infection, to the lower respiratory tract, kidneys, intestines and some visceral organs $[21,28]$.

A significant decrease in body weights $(P<0.05)$ at the end of the experiment was reported among all infected groups in compare to G5 and G6, where the vaccinated and infected groups (specially at the same time in G3) was more affected than that only infected with H9N2 (G4). Also, the bird weights in G4 significantly $(\mathrm{P}<0.05)$ differ by 9.2 and $9.9 \%$ than G5 and G6 respectively. In contrast, Costa-Hurtado, et al. [11] reported that no significant difference in body weight between control and groups either infected with H9N2 or vaccinated with NDV (LaSota).

Post-mortem lesions were more severe in chickens of G1 than other groups. The affected organs were trachea, thymus, bursa, spleen and kidney. These finding indicated that H9N2 not only affects respiratory and digestive systems but can also affects the immune organs (thymus gland and bursa of Fabricius) and kidney especially in cases of infected and LaSota vaccinated birds. However, the respiratory organs showed more prominent gross lesions in comparison to other organs. Similar findings were observed by Taubenberger and Morens [37]; Capua and Alexander [10] Hadipour, et al. [22] as well as Subtain, et al. [35]. However, the frequent cast formation in the tracheal bifurcation, which has been reported in field cases of H9N2 avian influenza outbreaks, was not observed in this experiment. 
H9N2 Tracheal Virual Shedding (Quantitative RT-PCR)

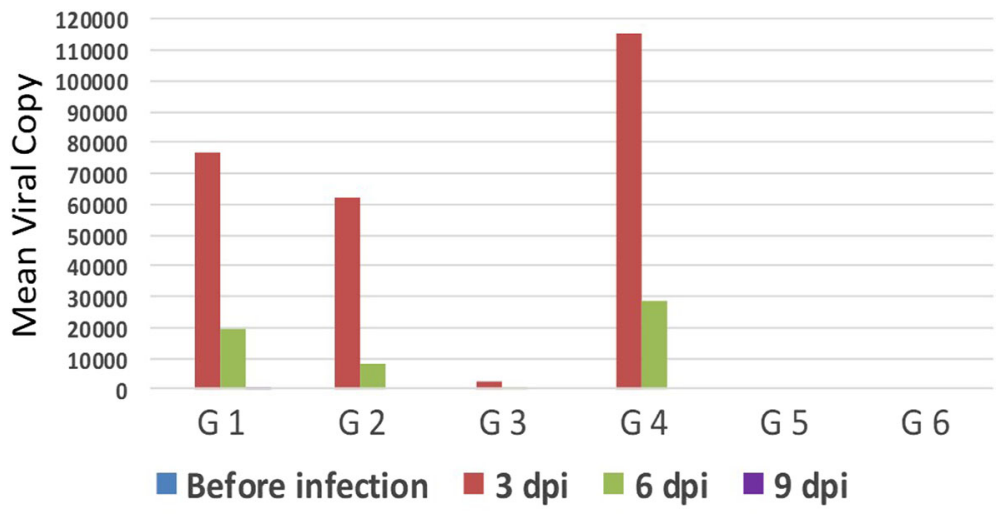

Fig. 7 Results of H9N2 shedding (just before infection, 3, 6 and 9 dpi) using quantitative RT-PCR

Alexander [2] reported that more cell injuries in the tissues of the respiratory system and gastrointestinal tract were recorded after infection with LPAIV. More severe lesions in the lungs and trachea could be attributed to the presence of a trypsin-like enzyme in the respiratory mucosa.

Histopathologically, chickens of G1 had severe of tracheal epithelial degeneration and hyperplasia of the mucosal lining compared to mild to moderate degree in G2, G3 and G4 which may be related to the higher late mortality obtained in this group along with obvious renal glomerulonephritis causing renal failure. This agreed with Aslam, et al. [4] who recorded an inflamed trachea and kidney of broilers infected with LPAI H9N2 and the histopathological lesions characterized by tracheal epithelial sloughing off with severe infiltration of inflammatory cells along with severe glomerular congestion of kidney.

Also, Doustar, et al. [15] proved in an experimental study that H9N2 virus could induce apoptosis and subsequent renal tissue damage. In addition, different mechanisms by which $\mathrm{H} 9 \mathrm{~N} 2$ can cause this effect were discussed in further investigations too [34, 40].

H9N2 infected birds (G4) also showed marked lymphoid depletion in the form of degeneration of thymocytes, follicular atrophy and cystic follicles of bursa of Fabricius and splenic lymphoid depletion. Similar results were reported by Kwon, et al. [24]. In addition, EL-bayoumi, et al. [16] reported about lymphocytic depletion and decreased immune response of birds infected $\mathrm{H} 5 \mathrm{~N} 1, \mathrm{H} 9 \mathrm{~N} 2$, and NDV.

Interestingly, the antibody titers against NDV (LaSotavaccine) were significantly decreased $(P<0.05)$ by the presence of H9N2 suggesting that NDV had insufficient replication to trigger the humoral response even though they were administered the typical vaccination dose of LaSota strain. Another explanation is the immunosuppressive effect of H9N2 that proved histopathologically as degeneration of thymocytes and lymphoid depletion of bursa and spleen. Also, Allawe [3] compared between LaSota vaccinated broiler chickens with or without H9N2 infection. At 40 days of age, the birds vaccinated with live NDV vaccines showed highest titers against ND in comparison with the vaccinated infected group with $\mathrm{H} 9 \mathrm{~N} 2$ that indicated the immunosuppressive effect of H9N2 infection.

Viral shedding patterns in tracheal swabs was detected for up to 9 dpi in birds of G1, while in all other groups shedding stopped on the $6 \mathrm{dpi}$. This may indicate that in case of NDV live vaccination after accidental unnoticed field infection with LPAI subtype H9N2 leads to prolonged shedding of $\mathrm{H} 9 \mathrm{~N} 2$ viruses compared with the case of NDV live vaccination before H9N2 field infection.

The least concentration of virus shedding (2630 virus copy/swab) appeared in G3 versus the highest concentration (115,300 virus copy/swab) in the non-vaccinated and infected group (G4) at 3dpi and 614 virus copy/swab compared to 28,500 virus copy/swab at $6 \mathrm{dpi}$ in both groups respectively, may turn out a possibility of some mechanism of interference between NDV live vaccines and H9N2 viruses in the respiratory tract of broiler chickens.

This may be related to the fact that LaSota vaccine and LPAI viruses replicate in cells where there are trypsin-like proteases such as in the upper respiratory and intestinal epithelium, so they might compete for the same target cells or replicate in adjacent cells [31, 36]. LaSota virus binds through the Haemagglutinin-Neuraminidase (HN) glycoprotein to sialic acid-containing receptors on the cell surface, as well as the HA glycoprotein does for LPAI-H9N2 [39]. This suggests that infection with a heterologous virus may result in temporary competition for cell receptors or susceptible cells, resulting in decreased initial replication of the second virus; but as replication of the first virus declines, the second virus increases to fill the gap [11].

Also, LaSota NDV strain is known to be a weak interferon inducer as part of their low virulent phenotype profile, local interferon production might still be able to interfere with LPAIV replication [14]. 
The results obtained underline the importance of co-infections, which can either exacerbate clinical disease or affect virus replication by lowering viral titers to under the levels of detection and affecting serological results and in some cases prolonged the time of virus shed which could favor for further transmission and these data was supported by Costa-Hurtado, et al. [12] and Ge, et al. [19] who concluded that, co-infection with NDV and HPAI can affect the viral replication dynamics and the disease caused by these viruses in chickens, but this effect will depend on the virulence of the viruses involved, the challenge titer of the viruses and the timing of the coinfections.

\section{Conclusions}

There was an adverse effect of combined infection with H9N2 and live LaSota vaccination in terms of clinical signs, body weights, mortality, histopathological lesions, viral shedding, and humoral immune response. Here we also recommend to diagnose the presence of H9N2 infection before ND vaccination to avoid to the exaggeration and immunosuppressive effect of H9N2 infection.

\section{Methods}

\section{Experimental animals}

A total of 130 one-day old commercial broiler chicks Cobb 500 purchased from a local poultry company (NASCO-Egypt) located in Alexandria governorate were used for the experimental infection in this study. All chicken groups were weighted at 14th, 21th, 28th and 35 th day of age. Study design and allocating animals to experimental groups are explained in Table 4.

All the experimental work, tests and procedures were complied with the general guidelines of Damanhour University and were approved by the Local Ethics Commission of the Animal Health and Welfare of Damanhour University with respect to care of animals under study and all efforts were made to minimize suffering. The Ethical Approval Code was DMU/VetMed-2017/ 0023.

\section{Housing and husbandry}

Chicks were housed in galvanized wire cages $(40 \mathrm{~cm}$ high $\times 50 \mathrm{~cm}$ width $\times 100 \mathrm{~cm}$ length) in (ten chicks each). Fresh feed and water were offered ad-libitum through the experimental period. All chicks were kept under the same managerial, hygienic and environmental conditions. Chicks were fed to cover their requirements according to NRC [38]. The sacrificed birds all over the experiment were previously anesthetized using sodium pentobarbital $(50 \mathrm{mg} / \mathrm{kg})$ by intraperitoneal injection to minimize suffering.

\section{Experimental procedures}

Vaccines. Birds of G1-4 were vaccinated against NDV by eye drop between days 15 th to 21 st (Table 4 ) using LaSota $^{\circ}$ (Schering plough, USA).

\section{Challenge virus}

Egyptian H9N2 strain isolated from broiler chickens in Alexandria Governorate (A/Chicken/Egypt/93/2015 and the GenBank accession No: KY872759) was used as a challenge virus in a dose $0.2 \mathrm{ml} /$ bird of $10^{6.3}$ EID50/dose ( $0.1 \mathrm{ml}$ by nasal instillation and $0.1 \mathrm{ml}$ through eye drop) at 18 th day of age [30].

\section{Sample size}

Ten chicks were sacrificed at the first day of age and serum samples were used to determine the level of maternally derived antibodies against H9N2 and NDV using Haemagglutination inhibition test. The remaining 120 chicks were distributed randomly into 6 equal groups of each 20 chicks. Birds were weighed and sacrificed by exsanguination after prior anesthesia.

\section{Experimental outcomes}

All the birds were examined daily for the following parameters:

a) Clinical signs, Mortality rates and Post-mortem (PM) lesions. Birds in all groups were examined daily up to 35 days of age and all disease signs,

Table 4 Experimental design

\begin{tabular}{|c|c|c|c|c|c|c|}
\hline Group & $\begin{array}{l}\text { Vaccination } \\
\text { with LaSota }\end{array}$ & Day of H9N2 infection & Weighting & Pooled tracheal swabs & $\begin{array}{l}10 \text { serum samples/group } \\
\text { (7th and } 14 \text { th dpi) }\end{array}$ & $\begin{array}{l}\text { Histopathology of } 2 \text { sacrified } \\
\text { birds at 4th and 9th dpi }\end{array}$ \\
\hline 1 & $18 \mathrm{DO}$ & $15 \mathrm{DO}$ & $14,21,28,35$ DO & $15,18,21,24 \mathrm{DO}$ & $22,29 \mathrm{DO}$ & $19,24 \mathrm{DO}$ \\
\hline 2 & $18 \mathrm{DO}$ & $18 \mathrm{DO}$ & & $18,21,24,27 \mathrm{DO}$ & $25,32 \mathrm{DO}$ & $22,27 \mathrm{DO}$ \\
\hline 3 & $18 \mathrm{DO}$ & $21 \mathrm{DO}$ & & $21,24,27,30$ DO & $28,35 \mathrm{DO}$ & $25,30 \mathrm{DO}$ \\
\hline 4 & - & $18 \mathrm{DO}$ & & $18,21,24,27 \mathrm{DO}$ & 25,32 DO & $22,27 \mathrm{DO}$ \\
\hline 5 & $18 \mathrm{DO}$ & - & & $21,28 \mathrm{DO}$ & $25,32 \mathrm{DO}$ & $22,27 \mathrm{DO}$ \\
\hline 6 & - & - & & $21,28 \mathrm{DO}$ & $25,32 \mathrm{DO}$ & $22,27 \mathrm{DO}$ \\
\hline
\end{tabular}

dpi, days post infection, DO Days Old 
mortalities and PM lesions of dead or sacrificed birds were recorded.

a) Histopathological examination. Two birds from each group were sacrificed under anesthesia with intravenous injection of sodium pentobarbital (50 $\mathrm{mg} / \mathrm{kg}$ ) at 4th and 9th dpi in groups (1-4) and at 22 and 27 days of age in groups 5 and 6. Samples from trachea, thymus, bursa, spleen and kidney were collected, fixed in 10\% formalin solution, stained with Hematoxylin and Eosin (HE) and examined for lesions [5].

b) Haemagglutination inhibition (HI) test. Serum samples collected at 7th and 14th dpi were tested by $\mathrm{HI}$ test for H9N2 and ND antibodies using standard haemagglutination antigens $\left(2^{8}\right.$ titers $)$ for both viruses. HI test was applied using 4 Haemagglutination Units (HAU) of the relevant antigens and $25 \mu \mathrm{l}$ of $1 \%$ chicken RBCs according to Alexander [2] and the results were analyzed using SPSS

c) Quantification of H9N2 virus shedding by RealTime RT-PCR (rRT-PCR). Pooled tracheal swabs were collected from 10 chickens in each group just before $\mathrm{H} 9 \mathrm{~N} 2$ infection then at day 3, 6 and 9 post H9N2 infections. The RNA was extracted using QIAamp viral RNA Mini-kits (QIAGEN 52904Germany) and the test was performed using rRTPCR (Strategen 3005P USA) with Quantitect RTPCR Kit reaction buffer (QIAGEN 204443-

Germany) and positive control RNA from A/quail/ Egypt/113413v/2011(H9N2). The Sequence of H9 primers and probe as published by Ben Shabat, et al. [7] were used.

d) Thermal profile was RT at $45^{\circ} \mathrm{C}$ for $10 \mathrm{~min}$ and $95^{\circ}$ $\mathrm{C}$ for $10 \mathrm{~min}$, followed by 40 cycles of PCR at $95^{\circ} \mathrm{C}$ for $15 \mathrm{~s}$ for denaturation and $60^{\circ} \mathrm{C}$ for $45 \mathrm{~s}$ for annealing and extension.

\section{Statistical methods}

Data of birds' body weight were subjected to analysis of variance procedures appropriate for a completely randomized design using the GLM procedures of SPSS (2008). The differences among means were determined using the student Newman keuls test. Statements of statistical significance are based on $p<0.05$.

\footnotetext{
Abbreviations

AIV: Avian influenza viruses; dpi: Day post infection; dpv: Day post vaccination; IBV: Infectious bronchitis virus; NDV: Newcastle disease virus; PM: Post-mortem; SPF: Specific pathogen-free
}

\section{Funding}

The authors extend their appreciation to the Deanship of Scientific Research at King Saud University for funding this work through a research group project (\# RG-1438-018).

\section{Availability of data and materials}

All the data supporting our findings are present within the manuscript. More information and supplementary files can be found through contacting Damanhour University Faculty of Veterinary Medicine, Department of Poultry and Fish Diseases at http://www.damanhour.edu.eg/vetfac/Pages/home.aspx.

\section{Authors' contributions}

Made substantial contributions to conception and design, or acquisition of data, or analysis and interpretation of data: HFE ARE HSA ARG. Been involved in drafting the manuscript or revising it critically for important intellectual content: ARE HFE HSA HMH MEA AAS IMS AA. Given final approval of the version to be published: HFE HSA ARE HMH ARG MEA IMS AAS AA. Agreed to be accountable for all aspects of the work in ensuring that questions related to the accuracy or integrity of any part of the work are appropriately investigated and resolved: ARE MEA HFE HSA HMH ARG IMS AAS AA.

\section{Ethics approval and consent to participate}

The experimental work, all tests and procedures complied with the general guidelines of Damanhour University and were approved by the Local Ethic Commission of the Animal health and welfare of Damanhour University with respect to care of animals under study and all efforts were made to minimize suffering. The Ethical Approval Code is: DMUNetMed-23/2017.

Consent for publication

Not applicable.

\section{Competing interests}

The authors declare that they have no competing interests.

\section{Publisher's Note}

Springer Nature remains neutral with regard to jurisdictional claims in published maps and institutional affiliations.

\section{Author details \\ ${ }^{1}$ Department of Poultry and Fish Diseases, Faculty of Veterinary Medicine, Damanhour University, Elgomhoria st, 63, Damanhour, Elbehira 22511, Egypt. ${ }^{2}$ Institute of Poultry Diseases, Free University Berlin, Königsweg, 63, 14163 Berlin, Germany. ${ }^{3}$ Department of Poultry, Faculty of Agriculture, Zagazig University, Zagazig 44511, Egypt. ${ }^{4}$ Department of Animal Production, College of Food and Agriculture Sciences, King Saud University, P.O. Box 2460, Riyadh 11451, Saudi Arabia. ${ }^{5}$ Department of Theriogenology, Faculty of Veterinary Medicine, Zagazig University, Zagazig 44511, Egypt. ${ }^{6}$ Department of Physiology, Faculty of Veterinary Medicine, Zagazig University, Zagazig 44511, Egypt.}

Received: 9 July 2018 Accepted: 9 November 2018 Published online: 20 November 2018

\section{References}

1. Aamir UB, Wernery U, Ilyushina N, Webster RG. Characterization of avian H9N2 influenza viruses from United Arab Emirates 2000 to 2003. Virology. 2007;361:45-55.

2. Alexander DJ. Avian Influenza - Diagnosis. Zoonoses Public Health. 2008;55: $16-23$.

3. Allawe AB. Study of effect of immunosuppresion caused by H9N2 in broiler. Iraqi J Vet Sci. 2008;32:80-9.

4. Aslam R, Aslam A, Tipu Y, Nazir J, Ghafoor A, Fatima S. Histopathological and immunohistochemical studies for the pathogenesis of a low pathogenicity $\mathrm{H} 9$ avian influenza virus in experimentally infected commercial broilers. J An Plant Sci. 2015;25:45-52.

5. Bancroft JD, Layton C. The hematoxylin and eosin. In: Suvarna SK, Layton C, Bancroft JD, editors. Theory practice of histological techniques. 7th ed. Philadelphia: Churchill Livingstone of El Sevier; 2013.

6. Banks J, Speidel EC, Harris PA, Alexander DJ. Phylogenetic analysis of influenza a viruses of $\mathrm{H} 9$ haemagglutinin subtype. Avian Pathol. 2010; 29:353-9. 
7. Ben Shabat M, Meir R, Haddas R, Lapin E, Shkoda I, Raibstein I, Perk S, Davidson I. Development of a real-time TaqMan RT-PCR assay for the detection of H9N2 avian influenza viruses. J Virol Methods. 2010;168:72-7.

8. Bonfante F, Cattoli G, Leardini S, Salomoni A, Mazzetto E, Davidson I, Haddas $\mathrm{R}$, Terregino C. Synergy or interference of a H9N2 avian influenza virus with a velogenic Newcastle disease virus in chickens is dose dependent. Avian Pathol. 2017:46:488-96

9. Capua I, Alexander DJ. Avian influenza: recent developments. Avian Pathol. 2004;33:393-404.

10. Capua I, Alexander D. Avian influenza and Newcastle disease: a field and laboratory manual. Milan: Springer-Verlag Italia; 2009.

11. Costa-Hurtado M, Afonso CL, Miller PJ, Spackman E, Kapczynski DR, Swayne DE, Shepherd E, Smith D, Zsak A, Pantin-Jackwood M. Virus interference between H7N2 low pathogenic avian influenza virus and lentogenic Newcastle disease virus in experimental co-infections in chickens and turkeys. Vet Res. 2014;45:1.

12. Costa-Hurtado M, Afonso CL, Miller PJ, Shepherd E, Cha RM, Smith D, Spackman E, Kapczynski DR, Suarez DL, Swayne DE, Pantin-Jackwood MJ. Previous infection with virulent strains of Newcastle disease virus reduces highly pathogenic avian influenza virus replication, disease, and mortality in chickens. Vet Res. 2015;46:97.

13. DaPalma T, Doonan BP, Trager NM, Kasman LM. A systematic approach to virus-virus interactions. Virus Res. 2010;149:1-9.

14. Dortmans JCFM, Koch G, Rottier PJM, Peeters BPH. Virulence of Newcastle disease virus: what is known so far? Vet Res. 2011;42:122.

15. Doustar Y, Mohajeri D, Nazeri M, Jafari B. Experimental study of lymphoid tissue apoptosis subsequent to infection by influenza virus (H9N2) in SPF chickens Asian. J Exp Biol Sci. 2012;3:87-92.

16. EL-bayoumi KM, Mahgoub KM, Mekky HM, Hassan ER, Amin Girh Z, Maatouq AM, El-Samadony HA, Rabie NS, MAA A, Kutkat MA. Molecular detection of H5N1, H9N2 and Newcastle disease viruses isolated from chicken in mixed infection in Egypt. World Appl Sci J. 2013;27:44-50.

17. El-Zoghby EF, Arafa A-S, Hassan MK, Aly MM, Selim A, Kilany WH, Selim U, Nasef S, Aggor MG, Abdelwhab EM, Hafez HM. Isolation of H9N2 avian influenza virus from bobwhite quail (Colinus virginianus) in Egypt. Arch Virol. 2012;157:1167-72.

18. Fusaro A, Monne I, Salviato A, Valastro V, Schivo A, Amarin NM, Gonzalez C, Ismail MM, Al-Ankari AR, Al-Blowi MH, Khan OA, Maken Ali AS, Hedayati A, Garcia Garcia J, Ziay GM, Shoushtari A, Al Qahtani KN, Capua I, Holmes EC, Cattoli G. Phylogeography and evolutionary history of Reassortant H9N2 viruses with potential human health implications. J Virol. 2011;85:8413-21.

19. Ge S, Zheng D, Zhao Y, Liu H, Liu W, Sun Q, Li J, Yu S, Zuo Y, Han X, Li L, Lv $Y$, Wang $Y$, Liu X, Wang Z. Evaluating viral interference between influenza virus and Newcastle disease virus using real-time reverse transcriptionpolymerase chain reaction in chicken eggs. Virol J. 2012;9:128.

20. Guo YJ, Krauss S, Senne DA, Mo IP, Lo KS, Xiong XP, Norwood M, Shortridge KF, Webster RG, Guan Y. Characterization of the pathogenicity of members of the newly established H9N2 influenza virus lineages in Asia. Virology. 2000;267:279-88.

21. Hablolvarid MH, Sohraby HI, Pourbakhsh SA, Gholami MR. Histopathological study of intranasally inoculated A/chicken/Iran/259/ 1998 (H9N2) influenza virus in chicken. Arch Razi Ins. 2004;58:51-62.

22. Hadipour MM, Farjadian SH, Azad F, Kamravan M, Dehghan A. Nephropathogenicity of H9N2 avian influenza virus in commercial broiler chickens following Intratracheal inoculation. J Anim Vet Adv. 2011;10:1706-10.

23. Haghighat-Jahromi M, Asasi K, Nili H, Dadras H, Shooshtari AH. Coinfection of avian influenza virus (H9N2 subtype) with infectious bronchitis live vaccine. Arch Virol. 2008;153:651-5.

24. Kwon J-S, Lee H-J, Lee D-H, Lee Y-J, Mo I-P, Nahm S-S, Kim M-J, Lee J-B, Park S-Y, Choi I-S, Song C-S. Immune responses and pathogenesis in immunocompromised chickens in response to infection with the H9N2 low pathogenic avian influenza virus. Virus Res. 2008;133:187-94.

25. Li Z, Chen H, Jiao P, Deng G, Tian G, Li Y, Hoffmann E, Webster RG, Matsuoka Y, Yu K. Molecular basis of replication of duck H5N1 influenza viruses in a mammalian mouse model. J Virol. 2005;79:12058-64.

26. Mo IP, Brugh M, Fletcher OJ, Rowland GN, Swayne DE. Comparative pathology of chickens experimentally inoculated with avian influenza viruses of low and high pathogenicity. Avian Dis. 1997;41:125-36.

27. Monne I, Hussein HA, Fusaro A, Valastro V, Hamoud MM, Khalefa RA, Dardir SN, Radwan MI, Capua I, Cattoli G. H9N2 influenza a virus circulates in H5N1 endemically infected poultry population in Egypt. Influenza Other Respir Viruses. 2013;7:240-3.
28. Mosleh N, Dadras H, Mohammadi A. Evaluation of H9N2 avian influenza virus dissemination in various organs of experimentally infected broiler chickens using RT-PCR. Iran J Vet Res. 2009;10:12-20.

29. Pantin-Jackwood MJ, Costa-Hurtado M, Miller PJ, Afonso CL, Spackman E, Kapczynski DR, Shepherd E, Smith D, Swayne DE. Experimental co-infections of domestic ducks with a virulent Newcastle disease virus and low or highly pathogenic avian influenza viruses. Vet Microbiol. 2015;177:7-17.

30. Reed $\sqcup$, Muench $\mathrm{H}$. A simple method of estimating fifty per cent Endpoints12. Am J Epidemiol. 1938;27:493-7.

31. Rott R. Molecular basis of infectivity and pathogenicity of myxovirus Brief review. Arch Virol. 1979:59:285-98.

32. Shakal M, Yi Y, Sa EZ. Surveillance on avian influenza H5N1 and H9N2 subtypes in Egypt 2012-2013. Poultry Fisher Wildlife Sci. 2014;2:1.

33. Suarez D. Newcastle disease, other avian paramyxoviruses, and avian Metapneumovirus infections. In: Swayne DE, editor. Diseases of poultry. USA: WILEY Blackwell; 2013. p. 87-138.

34. Suarez DL, Schultz-Cherry S. Immunology of avian influenza virus: a review. Dev Comp Immunol. 2000;24:269-83.

35. Subtain SM, Chaudhry ZI, Anjum AA, Maqbool A, Sadique U. Study on pathogenesis of low pathogenic avian influenza virus $\mathrm{H} 9$ in broiler chickens. Pak J Zool. 2011;43:999-1008.

36. Swayne DE, Halvorson DA. In: Saif YM, Barnes HJ, Glisson JR, Fadly AM, McDougald LR, Swayne DE, editors. Ames: Influenza: Diseases of Poultry lowa State Press; 2003. p. 135-60.

37. Taubenberger JK, Morens DM. The pathology of influenza virus infections. Ann Rev Pathol Mech Dis. 2008;3:499-522.

38. Umar S, Azeem T, Abid SA, Mushtaq A, Kiran A, Qayyum MR, Rehman A. Effect of lentogenic Newcastle disease virus (Lasota) on low pathogenic avian influenza virus (H9N2) infection in fayoumi chicken. J Avian Res. 2015;1:1-4

39. Wan Z, Ye J, Xu L, Shao H, Jin W, Qian K, Wan H, Qin A. Antigenic mapping of the hemagglutinin of an H9N2 avian influenza virus reveals novel critical amino acid positions in antigenic sites. J Virol. 2014;88:3898-901.

40. Wurzer WJ, Ehrhardt C, Pleschka S, Berberich-Siebelt F, Wolff T, Walczak H, Planz O, Ludwig S. NF- B-dependent induction of tumor necrosis factorrelated apoptosis-inducing ligand (TRAIL) and Fas/FasL is crucial for efficient influenza virus propagation. J Biol Chem. 2004;279:30931-7.

Ready to submit your research? Choose BMC and benefit from:

- fast, convenient online submission

- thorough peer review by experienced researchers in your field

- rapid publication on acceptance

- support for research data, including large and complex data types

- gold Open Access which fosters wider collaboration and increased citations

- maximum visibility for your research: over $100 \mathrm{M}$ website views per year

At $\mathrm{BMC}$, research is always in progress.

Learn more biomedcentral.com/submissions 